\section{First Indian remote-sensing satellite launched by Soviets}

New Delhi

INDIA's first operational remote-sensing satellite IRS-1 has gone into orbit after a successful launch from the Soviet cosmodrome at Baikanur on 17 March, an event Prime Minister Rajiv Gandhi described as "a major milestone in our space programme". With this, India has become the first developing country to have its own space-based system for natural resource management.

For the Soviet Union, the launch of the 980-kg Indian spacecraft was the first since its space business went commercial. The Indian Space Research Organisation (ISRO) will pay $\$ 6.5$ million for the launch, 25 per cent less than the price for similar services provided by the United States or the European Space Agency.

The \$50-million ISRO-built spacecraft

\section{Indian scientists too dependent on West}

New Delhi

Too much dependence on the West is one reason why Indian science is not able to tackle local problems, according to A.S. Paintal, president of the Indian National Science Academy (INSA). The academy has appealed to scientists to "think independently for ourselves" instead of working for honours from western nations which, says Paintal, maintains double standards - one for themselves, and another for Indians.

India has few institutions which can carry out research and development work in areas that should be receiving top priority. For example, Paintal says, nobody has thought of finding ways to reduce the temperature of workplaces to $28^{\circ} \mathrm{C}$, which alone would improve efficiency. No technologies have been developed to tap India's huge hydroelectric resources and applied work pertinent to national problems has been neglected.

One consequence of dependence on the West is that Indian scientists and their work are evaluated by western yardsticks, says Paintal. "We think an Indian scientist is good only if some western organization thinks he is good." Paintal says that this attitude is being exploited by western organizations by giving honours to those Indian scientists suited to their own needs.

Paintal also warns Indian scientists to be wary of being used as "covers for activities of the developed world". "Indian scientists must learn to think independently and should no longer be allowed to slog for some honour or favour of dubious merit and uncertain use to the country."

K.S. Jayaraman

carries three French-supplied linearimaging self-scanning cameras. From a height of $904 \mathrm{~km}$, they can take pictures of $148-\mathrm{km}$ wide scans in four spectral bands (0.4-0.9 micron) with a spatial resolution of 36 and 72. The polar Sun-synchronous orbit enables the satellite to revisit a fixed place on Earth once every 22 days. The IRS-1 data will be received at ISRO's ground station near Hyderabad, set up in 1979 to receive data from the US Landsat and augmented last year for reception from the French satellite Spot. Some 300 users, mostly in government agencies, have been identified for utilizing IRS-1

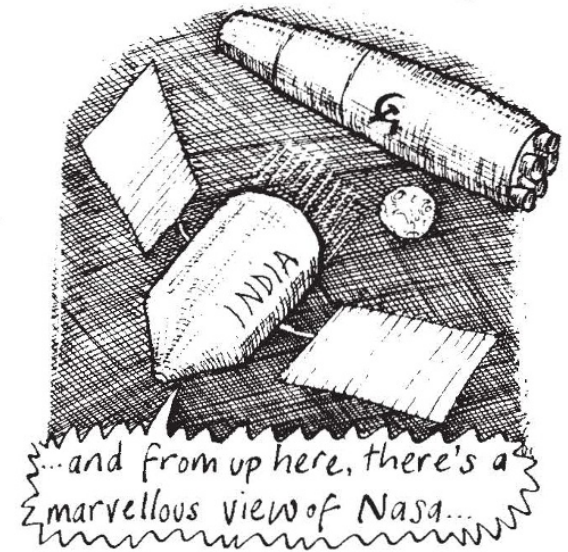

data products

According to ISRO, IRS- 1 is the first in the series of remote-sensing satellites it will put in orbit to form the space segment of the newly established national natural resources management system. The second IRS will also be launched from abroad but Indian's own rocket, PSLV, will launch IRS-3.

Operating the IRS system will cost India about $\$ 80$ million a year, a worthwhile investment in the context of increasing privatization of remote-sensing technology and possible disruption of services provided by foreign satellites. India is bitter about the rising cost of remotely sensed data products and considers the annual access fee of $\$ 600,000$ to Landsat as excessive. From ISRO's point of view, the launch of IRS-1 has brought India a step closer to its goal of self-reliance in a vital sector of the space industry that has so far been the preserve of the West.

IRS-1 cannot match Landsat or Spot in picture quality, but future satellites should carry higher-resolution cameras and a 'microwave eye' to see through clouds. ISRO believes India will capture a share of the remote-sensing market.

Space imaging has so far been used to map forests and identify wastelands, and the huge investment in remote sensing has yet to pay dividends for farmers. ISRO will not be ready before 1990 to apply this technique to more important tasks.

K.S. Jayaraman

\title{
Cash windfall for UK pioneers of MRI
}

\section{London}

Two British universities are this week grappling with the pleasing problem of how to carve up their share of more than $£ 3$ million in royalties arising from pioneering work on nuclear magnetic resonance imaging (MRI) over the past 15 years. The payments have been made to the universities of Nottingham and Aberdeen and to various individual scientists by the British Technology Group (BTG), a state-owned management company set up to help bring innovative ideas to the market-place. Money has been given to seven researchers with specific agreements with BTG. Precise sums are being kept secret.

Many of the basic techniques now used for diagnostic imaging were developed at the two universities between 1974 and 1980, with backing from the Medical Research Council and the universities themselves. The key inventions were patented by the National Research Development Corporation, now part of BTG. The main breakthrough on royalty payments was achieved in December 1986 when BTG accepted a substantial out-ofcourt settlement from the US healthcare company Johnson \& Johnson for infringement of patent. Six months later, after nearly two years of talking, BTG concluded an agreement with General Electric, of the United States, which included a down-payment of several million dollars the source of the money BTG has just paid out to Aberdeen and Nottingham.

BTG has a portfolio of 16 separate inventions on MRI. The main patent, developed by Peter Mansfield's team at Nottingham, is for the 'slice-selection' technique, which allows selective excitation and imaging of a specific cross-section of sample. More money is expected to come BTG's way as MRI technology continues to evolve with the consequent expansion of the market. At present, each MRI system costs around $£ 1$ million and more than 600 are installed worldwide. The MRI market from next year is expected to be worth between $£ 300$ million and $£ 600$ million annually.

Within the two universities, decisions on precisely how to spend the money have yet to be taken. Aberdeen's options are narrowed by its policy of splitting royalty cash three ways, with equal portions going to the department involved, individuals (weighted according to their contribution - "which can be difficult" concedes a university official) and the university's central funds. Simon Hadlington 